\title{
GESTÃO URBANA E ARRANJOS INSTITUCIONAIS PARA A POLÍTICA DE CICLOMOBILIDADE: PERSPECTIVAS DE AVANCCO NO CICLOTURISMO URBANO NA CIDADE DE CURITIBA, BRASIL
}

\author{
Urban management and institutional arrangements for the mobility cycle \\ policy: prospects for progress in urban bicycle tourism in the city of Curitiba, \\ Brazil
}

\author{
Yenifer Ninosca Silva Segovia \\ Doctoranda, Universidade Católica do Paraná \\ yenifersilvasegovia@gmail.com
}

\begin{abstract}
RESUMEN
A capacidade de articulação de política pública de mobilidade e turismo urbano em sistemas locais de gestão e governança tem sido colocada como desafio para a formulação de políticas urbanas cicloinclusivas em diferentes países. Nesse contexto, o objetivo do presente é delinear o contexto da ciclomobilidade de grandes cidades lationoamericas e compreender como órgãos e entidades públicas municipais responsáveis por políticas públicas de Curitiba associam a mobilidade urbana cicloinclusiva e atividades cicloturísticas. O estudo foi realizado a partir de base documental e de entrevistas com gestores municipais. Os resultados evidenciam, por um lado, fragilidades na articulação e formação de visões concordantes entre as entidades que compõem o sistema de governança e de gestão urbana local responsável por incentivar, regular e aplicar recursos públicos na atividade cicloturística urbana e, por outro, riscos elevados para aumentar a utilização de bicicletas no sistema urbano viário de Curitiba.
\end{abstract}

Palabras clave: gobernanza urbana, políticas públicas, ciclo movilidad urbana, cicloturismo.

Bloque temático: espacio público y proyecto urbano en la metrópolis contemporánea.

\begin{abstract}
The capacity for articulating public policies for mobility and urban tourism in local management and governance systems has been challenged for the formulation of cycle-inclusive urban policies in different countries. In this context, the purpose of this paper is to outline the context of the cyclomobility of large Latin American cities and to understand how municipal public bodies and entities responsible for public policies in Curitiba associate urban mobility and cyclotourism activities. The results show, on the one hand, weaknesses in the articulation and formation of concordant views between the entities that make up the system of governance and local urban management responsible for encouraging, regulating and applying public resources in urban cyclotourism activity and, on the other hand, high risks to increase the use of bicycles in the urban road system of Curitiba.
\end{abstract}

Keywords: urban governance, public policies, urban mobility cycle, cycle tourism.

Topic: public space and urban project in the contemporary metropolis. 


\section{Introdução}

Tentativas de desenvolver arranjos institucionais mais eficazes para responder a mobilização e participação de cidadãos em políticas públicas são atuais, embora tenham trajetória relativamente longa e em diferentes contextos (Hague \& McCourt, 1974; Hourihan, 1987; Tunstall, 2001; Singh, 2006; Henningsson et al., 2014; Nousiainen \& Mäkinen, 2014; Kull \& Tatar, 2015; Radzik-Maruszak \& Bátorová, 2015). No caso brasileiro, o desenvolvimento de arranjos institucionais mais permeáveis à inserção de demandas mais democratizadas também já tem uma trajetória considerável (Bordenave, 1995; Dowbor, 2001; Guerra, 2002; Frey, 2007; Goulart, Terci, \& Otero, 2016). Por exemplo, a partir dos municípios e com a democratização da defesa de interesses setoriais e locais, a Constituição brasileira de 1998 deu início à formação de arranjos institucionais para dar suporte a políticas de desenvolvimento urbano no Brasil, o que avançou com a criação do Ministério das Cidades, em 2003. A partir disso, as discussões passaram a ser encaminhadas mais consistentemente até que, entrou vigência em 2012 a lei federal que instituiu a Política Nacional de Mobilidade Urbana, criando possibilidades de participação cidadã. Entretanto, as cidades brasileiras, salvo raras exceções, ainda não avançaram suficientemente nessa política para posicionar a bicicleta com uma alternativa importante para o transporte público e, menos ainda, para o turismo urbano.

No caso específico da bicicleta como modal de transporte, apesar de apresentar reflexos positivos na qualidade de vida nas cidades - por exemplo, ao mitigar problemas de poluição ambiental e sonora (Zhang, Zhang, Duan, \& Bryde, 2015), melhorar a saúde de usuários, servir de alternativa de recreação, permitir maior liberdade no deslocamento (Jacobsen, 2003; Winters, Teschke, Brauer, \& Fuller, 2016) - ainda carece de melhor compreensão de particularidades sociais e infraestrturuais de diferentes contextos urbanos. Nesse sentido, objetivo do presente é delinear o contexto da ciclomobilidade de grandes cidades lationoamericas e compreender como órgãos e entidades públicas municipais responsáveis por políticas públicas de Curitiba associam a mobilidade urbana cicloinclusiva e atividades cicloturísticas.

O estudo se justifica por Curitiba, apesar de possuir um sistema de transporte modelar para muitas cidades brasileiras e estrangeiras, ainda apresentar problemas para utilizar bicicletas no sistema de mobilidade urbana, como atestam, por exemplo, os estudos de Duarte et. al. (2014), Ríos et. Al. (2015) Andrade et. al. (2016). A investigação pode contribuir para (i) explicitar a trajetória histórica da relação entre discursos de políticos e a eficiência na formação e utilização da infraestrutura cicloviária da cidade, (ii) identificar como a mobilização social e órgãos setoriais influenciam políticas públicas cicloinclusivas de atividades cicloturísticas, e para (iii) compreender porque Curitiba possui um baixo número de usuários de bicicletas.

\section{Gestão e governança urbana}

A busca global de melhores padrões de gestão urbana (Stubbs, Lemon, \& Longhurst, 2000; Wong, Tang, \& van Horen, 2006; Dijk, 2007; Bačlija, 2013; Zamani, Shali, Miralanaq, \& Hadi, 2014) também se destaca nas agendas dos governos de África, Ásia e América Latina (Campbell \& Fuhr, 2004; Duarte \& Frey, 2008; Rosa, Procopiuck, \& Frey, 2016), mesmo que ainda existam limitações para os projetos urbanos e a gestão política das cidades resolverem graves problemas que persistem nas cidades. Surgem, entretanto, perspectivas promissoras para reduzi-los quando os governos agem procurando compreender a situação contextual cambiante e, em função disso, se ajustarem a forças sociais locais para elevar a eficiência das cidades para melhorar a qualidade de vida das pessoas (Hernández, 2004, p. 327).

Nesse contexto, grandes cidades latino-americanas, como Bogotá e Buenos Aires e algumas cidades do Brasil e México, avançam para a descentralização política, a participação dos cidadãos e a autonomia local. Isso tem incentivado a formação de alianças estratégicas para o desenvolvimento de macroprojetos para formar novas bases econômicas, de infraestrutura, de qualidade de vida, de integração social e de governança urbana (Febres-Cordero, 2011, p. 185). É um ambiente em que o ato de governar tende a ocorrer em meio a relações mutuamente constitutivas, condicionado pela identidade sociocultural da cidade e associada com práticas, lutas 
e oportunidades originadas da vida social cotidiana (Mccann, 2017). Essa forma interativa de conduzir interesses públicos tem se tornado fértil para a formação de arranjos de governança urbana societal, como expressão inovadora para a estruturação e organização de funções públicas e privadas emergentes de valores específicos de agrupamentos humanos relativamente autônomos e implexos em contextos urbanos para identificar e encaminhar democraticamente políticas públicas para solução de problemas coletivos de qualidade de vida nas cidades.

A perspectiva da governança urbana societal está estreitamente vinculada à concepção de governança de Jan Kooiman (2005), ou seja, sobre amplas tendências sociais pautadas em processos de diferenciação e integração. Esses processos resultam da ampliação de cadeias de interdependência institucionalizadas para dar suporte à atuação de um grande número de agentes sociopolíticos em crescente interação. Essa interação ocorre em contextos em que as clássicas divisões entre interesses públicos e privados se tornam indefinidas. É, portanto, esperado que ocorram mudanças profundas nos papeis dos governos para que passem a cooperar com outros atores sociais, tornando obsoletas as tradicionais intervenções governamentais (Kooiman, 2005, pp. 57-58). Quando se trata da governança urbana societal, há ainda aproximação da concepção de Kooiman e Vliet (2000), no sentido da dependência de formação de um autogovernos locais e com forte capacidade de mobilização social. Nesses autogovernos, os atores, representando de diferenciados grupos sociais, ou mesmo de setores tradicionais da sociedade, encontram espaços inovadores para interagir para resolução de problemas, criação oportunidades e formação de arranjos institucionais para fazê-los.

A gestão urbana tem, portanto, um caráter fundamentalmente sociopolítico que busca coerência, racionalidade e criatividade em políticas públicas inovadoras para gerar e direcionar impactos para a cidade como um todo (Febres-Cordero, 2011). Além disso, a gestão urbana tem como função fundamental a criação de equilíbrio entre a frágil coexistência do desenvolvimento social, econômico e ambiental. Esse equilíbrio pode ser obtido por meio de cinco dimensões: a descentralização, participação, gestão autônoma, desenvolvimento sustentável e competitividade da cidade (Bačlija, 2010). Essa atuação multifacetada visa coordenar e integrar ações públicas e privadas para tornar a cidade mais competitiva, equitativa e sustentável a partir da resolução de problemas urbanos de modo integrado (Dijk, 2007). Nessa perspectiva, o conceito de gestão apareceu na década de 1990, como uma abordagem que pretende dar conta das transformações de variados assuntos com uma incidência pública de qualidade e especificamente nas políticas públicas urbanas conduzidas mais democraticamente (Vásquez Cárdenas, 2013, p. 220).

\section{Curitiba no contexto das políticas públicas cicloinclusivas na América Latina}

No campo político brasileiro, a Constituição Federal de 1988, ao atribuir competência específica para a União estabelecer diretrizes para os transportes urbanos (art. 21, inc. XX) e atribuir a execução da política de desenvolvimento urbano para os municípios, mas a partir de diretrizes especificadas em lei (art. 182), abriu caminhos para a promulgação da Lei Federal 12.587, em 13/04/2012. Esta lei instituiu a Política Nacional de Mobilidade Urbana, que priorizou os modos não motorizados e do transporte público coletivo em contextos urbanos, estabeleceu padrões de emissão de poluentes, instituiu a gestão democrática e o controle social do planejamento e da avaliação da política de mobilidade. Isso fez com surgisse nos municípios a necessidade de o gestor urbano "fazer seus planos, a sociedade civil participar e os operadores de direito fiscalizar o processo" (ITDP, 2012). Mesmo antes de o Estado brasileiro passar a orientar políticas públicas por meio de lei específica, o uso da bicicleta no Brasil vinha ganhando relevância desde a criação do Ministério das Cidades, em 2003. Este ministério passou a impulsionar a inserção da bicicleta como alternativa importante para a mobilidade urbana, como, por exemplo, realizando, em 2003, a primeira reunião para obtenção de informações a partir de discussões sobre uso da bicicleta no pais. Naquela reunião, procurou-se estimular a sociedade civil para o desenvolvimento da política cicloviária e sua inserção social (Xavier, 2007, pp. 130-131; Ferro, 2013).

Em avaliação realizada em 2007 pelo Ministério das Cidades foi constatado que a maioria dos deslocamentos urbanos era realizada a pé e por meio de bicicletas nas cidades com menos de 50 mil habitantes, que 
representam mais de $90 \%$ do total das cidades brasileiras. Nessas cidades a bicicleta era o veículo individual mais utilizado concomitantemente com eventuais de linhas de transporte coletivo. Essas linhas operavam normalmente em condições precárias, frente a limitação da demanda pela baixa concentrada e as curtas distâncias de deslocamento (SNTMU, 2007, p. 22). Esse contexto de mobilidade urbana mudava quando se tratava de grandes cidades que possuíam elevada oferta de transporte coletivo associada com a alta densidade e maior agressividade do tráfego de veículos motorizados, bem como ao maior tempo despendido nos deslocamentos diários. Nesses grandes centros, as bicicletas eram mais presentes nas áreas periféricas em que as condições precárias de mobilidade propiciadas pelos transportes coletivos se assemelhavam às encontradas nas cidades médias (SNTMU, 2007, p. 22).

Em perspectiva mais promissora para o modal bicicleta, em 2015 um estudo patrocinado pelo Banco Interamericano de Desenvolvimento (BID) nas cidades latino-americanas e Caribe constatou que o uso da bicicleta como meio de transporte urbano vem crescendo significativamente. Esse crescimento tem contribuído para melhorar a mobilidade, a equidade e o acesso a oportunidades socioeconômicas pelos cidadãos. No caso das cidades, o uso da bicicleta pode elevar a competitividade e configura uma alternativa importante para reduzir problemas de congestionamento do trafego, da má qualidade do ar e das emissões de gases responsáveis pelas mudanças climáticas. Entretanto, a materialização desses benefícios nas cidades depende de dotação de infraestrutura cicloviária, participação dos moradores locais na formulação de políticas públicas que incentivem, regulem e ofereçam informações necessárias para monitorar o desempenho do uso desse modal (Ríos Flores et al., 2015).

Os dados obtidos no estudo de Ríos Flores et al. (2015), quando associados com a densidade demográfica demonstram, conforme Gráfico 1, que cidades de baixa densidade tendem a ter maior número de viagens de bicicleta. Isso pode estar associado à maior ou menor disponibilidade de transporte coletivo de qualidade ou, ainda, ao menor risco gerado para os usuários de bicicleta pelo trânsito motorizado. No que diz respeito à avaliação da eficiência da utilização de infraestruturas cicloviárias, tal gráfico mostra que as variáveis densidade demográfica e extensão da estrutura cicloviária podem se mostrar como indicadores importantes para avaliar o resultado percentual de viagens realizadas.

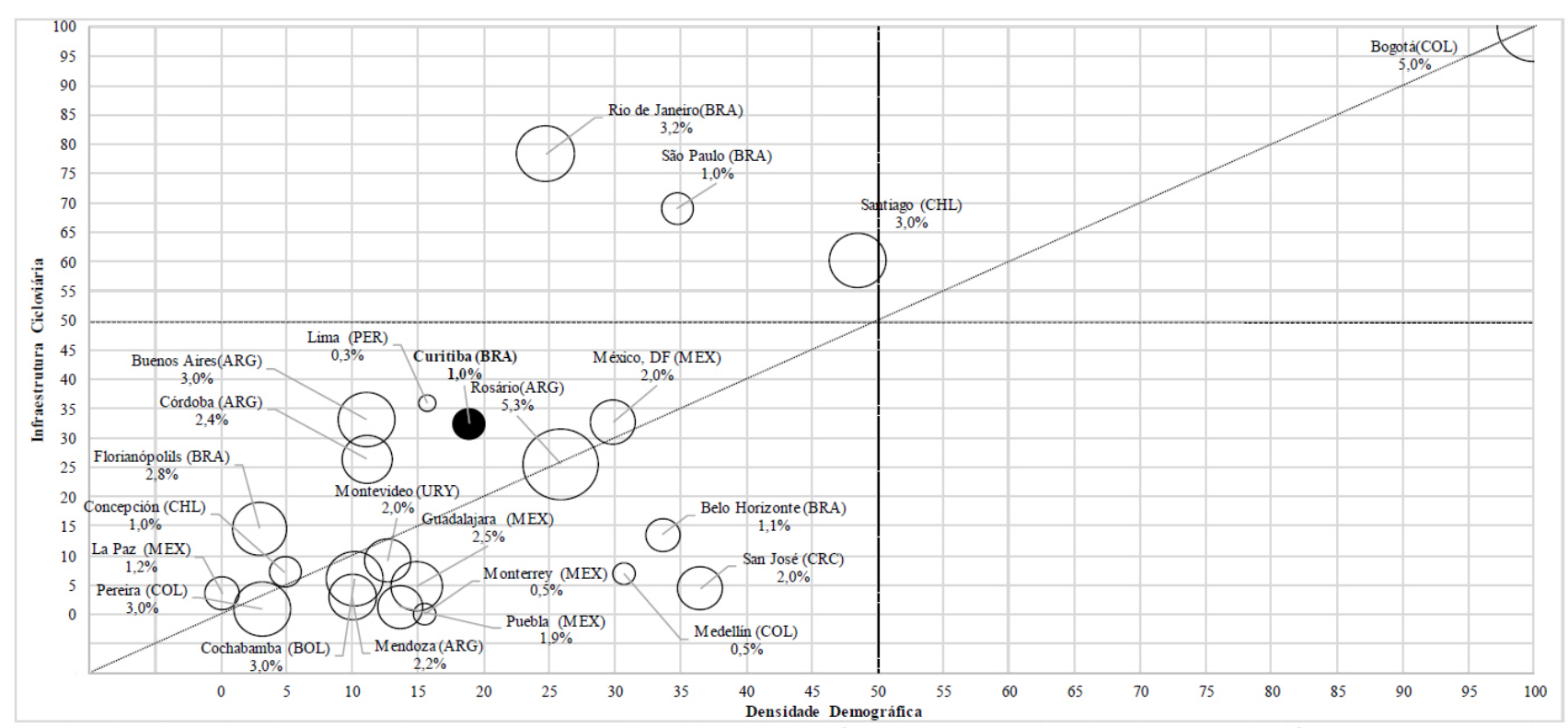

Gráfico 1 - Classificação as cidades em função da densidade demográfica, extensão da infraestrutura cicloviária e do percentual de viagens por bicicletas. 
A classificação mostrada no Gráfico 1 sugere, por um lado, que um maior o número de viagens em menor infraestrutura pode ser um bom indicador da intensidade com que tal infraestrutura cicloviária é utilizada. Por outro lado, em grande parte das cidades, o maior número de viagens com menor densidade demográfica pode indicar que a utilização da infraestrutura cicloviária pode se mostrar mais competitiva em termos de benefícios para os usuários em relação ao transporte público motorizado. De acordo com Gráfico 1, Curitiba tem menor eficiência da infraestrutura cicloviária quando comparada com outras opções de mobilidade urbana. A partir do contexto que demonstra a importância da utilização do modal bicicleta em cidades latino-americanas é que procura-se conhecer mais profundamente como a cidade de Curitiba tem conduzido suas políticas públicas, bem como os seus sistemas de governança e de gestão urbana têm se comportado. Essa discussão é importante porque, no caso de Curitiba, há duas frentes para avançar: (I) políticas públicas que busquem intensificar a utilização da infraestrutura existente e (II) políticas públicas que visem ampliar extensão de tal infraestrutura. Dentre as duas, conforme mostra o Gráfico 1, em tese, seriam mais eficientes políticas públicas para motivar que tal infraestrutura seja utilizada mais intensamente em termo de proporção em relação ao número total de viagens na cidade.

\section{Metodologia}

O corpus de análise foi formado por uma base documental (Fase 1) obtida no Instituto de Pesquisa e Planejamento Urbano de Curitiba (IPPUC) e por um conjunto de entrevistas em profundidade (Fase II) realizadas durante os meses de novembro e dezembro do ano 2016. As entrevistas foram realizadas com representantes de áreas técnicas dos seguintes órgãos da Prefeitura Municipal de Curitiba: área de Mobilidade Urbana da Secretaria Municipal de Transporte (SETRAN); área de Ciclo Mobilidade do Instituto de Planejamento e Pesquisa de Curitiba; área de relações públicas e de turismo do Instituto Municipal de Turismo (IMT), e do programa Ciclolazer da Secretaria Municipal de Esporte, Lazer e Juventude (SMELJ). Durante a entrevista procurou-se confrontar ou confirmar informações obtidas de uns entrevistados em relação às declarações de outros.

\section{Apresentação e análise dos resultados}

A apresentação e análise dos resultados ocorrem em dois momentos nas seções que seguem. Primeiro, foi reconstruída a trajetória histórica da política pública de ciclomobilidade de Curitiba a partir da análise documental. No segundo, tendo como base as entrevistas em profundidade, foram tratadas as relações intersetoriais a partir das quais instituições e órgãos públicos municipais de Curitiba se articulam para viabilizar políticas públicas de ciclomobilidade, com foco voltado para atividades de cicloturismo urbano.

\subsection{Histórico do desenvolvimento da formação da infraestrutura cicloviária de Curitiba}

O primeiro estudo sobre utilização da bicicleta como meio de transporte urbano para Curitiba foi realizado em 1977, intitulado como "Planejamento cicloviário: uma política para bicicletas". Começava-se, então, a "integrar a bicicleta no planejamento do sistema viário de Curitiba [...]. A classe operária (...) representa[va] a maioria dos usuários de bicicleta" (IPPUC, 1977, p. 1) e, por isso, procurava-se viabilizar o deslocamento principalmente para nova Cidade Industrial. A estimativa foi de que existiam 112.000 bicicletas, que resultaram do incremento anual de 10.000 bicicletas desde 1963. A maior parte dos compradores de bicicletas pertencia à classes média e as utilizava para principalmente para fins de lazer. Também foi constatado que o comprador de baixa renda só comprava a bicicleta quando tinha certeza de de o investimento seria imediatamente amortizado com a redução dos gastos em transporte. O estudo revelou que mais de $60 \%$ das famílias possuíam bicicletas e que havia tendências de elevação de tal porcentual. A conclusão foi de que, se o sistema cicloviário fosse lançado e devidamente promovido, seria possível levar às ruas da cidade uma grande frota inativa de bicicletas (IPPUC, 1977). 
Em 1995, foi publicado o trabalho chamado "Estudo preliminar sobre o perfil do ciclista da rede de ciclovias de Curitiba", que resultou da aplicação de 3.758 questionários. Existiam, então, 85,33 km de ciclovias para fins de laser e de transporte de trabalhadores urbanos. A intenção era de, a médio prazo, ampliar a ciclovias para $150 \mathrm{~km}$. A avalição da rede de ciclovias ocorreu sob o ponto de vista dos usuários. A intenção era estabelecer diretrizes para consolidar a política pública de planejamento cicloviário para lazer e para a integração como transporte alternativo ao sistema de transporte da cidade. Os resultados confirmaram a previsão de 1977 de que $60 \%$ das famílias curitibanas possuíam bicicleta. Foi constatado que, em dias úteis da semana, 51\% dos usuários tinham renda igual ou menor a 3 salários mínimos. Entre os usuários de final de semana, 70\% tinham renda superior a três salários mínimos, possuíam o maior número de bicicletas e moravam na região central da cidade. Durante os dias de semana, os destinos eram regiões com concentração de prestação de serviços e de comércio e indústrias. Nos finais de semana, os destinos eram os bosques, parques e praças públicas (IPPUC, 1995).

Em 2008, quando se executava um embrionário Plano Diretor de Ciclovias, Curitiba contava com 116km de ciclovias ( $81 \mathrm{~km}$ de ciclovias em calçadas compartilhadas e $35 \mathrm{~km}$ de ciclovias exclusivas). Naquela época era projetada a ampliação de mais $22,5 \mathrm{~km}$ na malha total. Essa malha chegaria, portanto, a 138,5km (PMC, 2008, p. 23). A relativamente pouca expressividade da ampliação da infraestrutura cicloviária com base em ações planejadas internamente ao poder público começou a ser contestada a partir de 2005, com o surgimento de movimentos de ciclistas. Esses movimentos culminaram, por exemplo, com a fundação, em 2011, da Associação de Ciclistas do Alto Iguaçu (Ciclolguaçu), que é uma organização sem fins lucrativos para fomento da cultura da bicicleta como meio de transporte em Curitiba e região metropolitana. Um momento marcante de embates entre ciclistas e a Prefeitura Municipal pode ser ilustrado com o seguinte relato: em "[...] 22 de setembro de 2007, um grupo de ciclistas fez a primeira ciclofaixa de Curitiba, a ciclofaixa pirata da Augusto Stresser, ciclofaixa clandestina. Ela foi objeto de um processo administrativo da Prefeitura por crime ambiental, por pichação [...] e fizemos uma festa para arrecadar o valor da multa por crime ambiental" (Nataraj, 2014, p. 5). A finalidade desse protesto foi "mostrar para os gestores a importância do planejamento da bicicleta na rede de transporte da cidade" (Idem).

Quanto à atuação unilateral do poder público municipal expresso no discurso histórico sobre o transporte coletivo de Curitiba, também passou a ser recentemente objeto de contestações, como as que seguem: "a mobilidade não motorizada jamais se viu favorecida nos eixos estruturais, [o planejamento] favoreceu o transporte coletivo, o progresso industrial da Volvo com certeza, mas não a bicicleta. Nos eixos estruturais não há espaço para bicicleta e não há espaço para o pedestre. [...] "As calçadas têm oitenta centímetros, um metro" (Jaruga, 2014, p. 8). De acordo com conteúdo do Plano Cicloviário de Curitiba 2013 (PMC, 2016), que procurou incorporar as discussões promovidas por movimentos de ciclistas, a previsão era que, em 2016, Curitiba passaria de $127 \mathrm{~km}$ para $300 \mathrm{~km}$ de vias cicláveis. Com a expansão seriam criados $90 \mathrm{~km}$ de ciclorotas (vias de tráfego comum e de baixo movimento, com sinalização horizontal e vertical para indicar a presença de ciclistas e obrigar os motoristas a dirigir com menor velocidade), $80 \mathrm{~km}$ de vias calmas (com velocidade máxima para veículos motorizados reduzida e com circulação de ciclistas em áreas demarcadas) e 130km com vias cicláveis (ciclofaixas e passeios compartilhados entre pedestres e ciclistas).

\subsection{Lacunas entre discurso e prática na formação da infraestrutura cicloviária}

Considerando os dados apresentados e discutidos até este ponto, o Gráfico 2 demonstra o crescimento médio anual real infraestrutura cicloviária de Curitiba. De 1983 a 1993, o crescimento foi de 4,3\%; de 1993 a 1995 de 11,2\%; de 1995 a 2008 de 2,4\%; de 2008 a 2013 de 1,8\%; e de 2013 a 2016 de 15,4\%. A taxa média anual desse crescimento entre 1983 e 2016 foi de 4,5\%. O Gráfico 2 apresenta os valores absolutos que deram origem a esses percentuais de crescimento. 


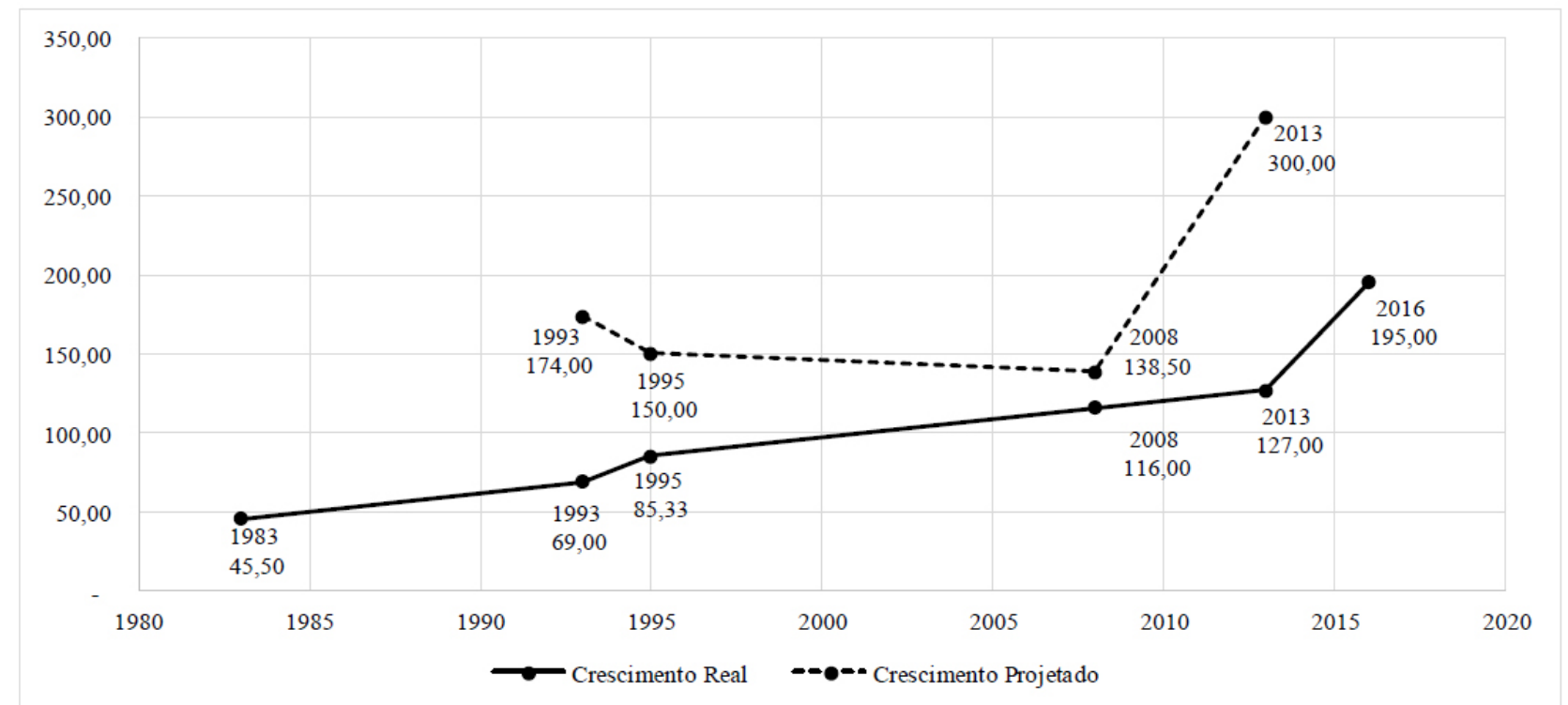

Gráfico 2 - Comparativo entre crescimento real e projetado da infraestrutura cicloviária de Curitiba (1983-2016)

No Gráfico 2 são mostradas também as previsões trazidas nos planos para expansão da infraestrutura cicloviária. Considerando a relação entre previsão e efetiva implementação de infraestrutura cicliviária em Curitiba, o alcance das metas para o período 1993 e 1995 foi de apenas 49\%, de 1995 a 2008 de 77\%, de 2008 a 2013 de $92 \%$ e de 2013 a 2016 de 65\%. À exceção do período de 2008 a 2013, os dados evidenciam que, historicamente, sempre houve um superdimensionamento dos planejadores da cidade sobre as possibilidades reais de crescimento da infraestrutura cicloviária. Sobre os planos de expansão, o coordenador do Plano Cicloviário de Curitiba, vinculado ao IPPUC, expressando uma possível explicação sobre essas lacunas históricas entre o planejado e o executado, afirmava que "Eu sempre digo isso, meta é uma coisa para perseguirmos, ela não depende às vezes só de um gestor ou de uma pessoa, caso consigamos atingir é uma maravilha, é formidável" [...] "Caso contrário, estamos na previsão e nos obrigamos a corrigir números e rumos. Os trezentos quilômetros é uma meta. Meta é isso, meta é um anseio, uma vontade, nós fazemos tudo para poder chegar lá, mas se não conseguirmos vamos corrigir rumos ou passar um pouco para adiante, isso não é uma camisa de força" (Miranda, 2014, p. 10).

\subsection{A articulação entre órgãos públicos para o desenvolvimento do cicloturismo}

O cicloturismo é uma das possibilidades de tornar a cidade mais atrativa turisticamente e, ao mesmo tempo, de incentivar a cultura da utilização da bicicleta na cidade. Essa política de incentivo, se devidamente articulada e por meio de ações concretas para reduzir os riscos para ciclistas na cidade, poderia ser um dos meios de melhorar o índice de utilização da infraestrutura ciclviária existente. Essa infraestrutura tem sido, pois, subutilizada quando comparada com outras cidades (vide, por exemplo, o Gráfico 1). Nesse sentido, por meio de entrevistas, procurou-se compreender como estavam estruturadas as políticas públicas

e os sistemas de gestão urbana encarregados de fomentar conjunta e articuladamente as atividades turísticas associadas com a utilização da bicicleta em Curitiba. A SETRAN relatou que, em relação à área do cicloturismo, possuía aproximação com Instituto Municipal de Turismo (IMT) para prestação de apoio em iniciativas do Instituto, o que se refletiu em algumas ações concretas. Exemplos disso foram a criação conjunta das rotas cicloturísticas Curta Curitiba, by Bike" e "Poty by Bike". Essas rotas foram criadas para propiciar segurança e conforto para moradores locais e turistas (SETRAN). O IMT, por sua vez, confirmou essa aproximação, informando que a SETRAN também tinha uma função importante como consultora normativa e no apoio operacional para eventos realizados na cidade, não necessariamente na área do cicloturismo. Existia também um projeto de cicloturismo em desenvolvimento pelas duas instituições para integrar municípios da Região 
Metropolitana de Curitiba (RMC). Quanto ao envolvimento de outras instituições nesse projeto, o IMT avaliou que havia nível de articulação bastante baixo (IMT).

Quanto à condução de atividades conjuntas por gestores públicos e outros atores chaves para potencializar o alcance de resultados satisfatórios para a cidade, a avaliação foi de que as articulações entre a SETRAN e o IMT ainda não eram suficientemente sólidas. A comunicação fluída e ativa era bastante deficiente entre tais a agentes e atores para incentivar o uso da bicicleta, não somente como modal de transporte, mas também com fins de lazer e turísticos. Da entrevista com o IPPUC foi evidenciado que não existiam articulações com a área municipal de turismo que permitissem o desenvolvimento de projetos de ciclomobilidade para o turismo. Entretanto, houve reconhecimento de que seriam pertinentes e necessárias articulações mais efetivas com o IMT para obtenção de resultados práticos na área do cicloturismo. Havia, por exemplo, espaços para maior proximidade da relação entre a bicicleta e o turismo pela existência do projeto Circuito Interparques (IPPUC). O IMT exemplificou a existência de vínculos com IPPUC por meio de uma ação específica desenvolvida para a formulação de um mapa turístico para a cidade. Na criação desse mapa pretendia-se incorporar as ciclovias existentes. Entre essas duas instituições foi possível observar laços relacionais ainda bastante frágeis quando se considerou a dimensão das ações concretas desenvolvidas, principalmente pela informalidade como eram tratadas. As ações se mostraram bastante limitadas e o nível de vínculo e o trabalho conjunto na política pública ciclo inclusiva era relativamente segregado. Quando ocorriam, as ações tendiam a ser pontuais e voltadas mais para ajustar questões de cunho burocrático em projetos do que para estabelecer diretrizes ou intercâmbio de recursos mais amplos.

De modo geral, quanto ao cicloturismo, não foi possível constatar ações com articulações sólidas entre a SETRAN, o IPPUC e o IMT. As relações envolvendo essas três organizações foram caracterizadas mais por manifestação de ações futuras do que demonstração de resultados concretos. Nesse conjunto de organizações públicas, o cicloturismo urbano não foi identificado no planejamento de diretrizes ou ações como elemento que pudesse contribuir para a dinamização da atividade turística na cidade. Em relação ao Conselho Municipal de Turismo de Curitiba (COMTUR), no IMT a avaliação era de que, apesar de ambos fazerem parte da área de turismo no município, não existia parceria sólida entre as duas organizações. As relações eram estabelecidas normalmente com base na troca de relatórios, em ações de fiscalizações e na definição de algumas diretrizes e normas de trabalho para o IMT, sem, portanto, uma participação mais efetiva na realização dos projetos (IMT). Considerando que a gestão urbana depende de ações e decisões

da municipalidade que, de forma direta ou indireta, possam transformar o espaço local e impactar na vida dos moradores e usuários, a relação entre esses dois órgãos pareceu ainda bastante distante disso. Portanto, ainda eram bastante incipientes os esforços para que se conseguissem interações com solidez suficiente para que pudessem incentivar a atividade do cicloturismo urbano em Curitiba.

\section{Conclusão}

Avanços do entendimento sobre a importância de perspectivas como a governança urbana societal estão abrindo espaços para a inserção da gestão urbana como meio de articulação entre entes públicos, privados e do terceiro setor para formulação de políticas públicas e sua execução por meio de leis, programas, projetos e ações, considerando impactos ambiental, social e econômicos no desenvolvimento local. Na presente investigação ficou evidenciado que as instituições públicas precisam criar mecanismos de incentivo ao trabalho articulado entre as suas funções, bem como para que os órgãos se tornem mais permeáveis a influências de atores sociopolíticos externos (moradores, ativistas, organizações da sociedade civil, empresas etc.) interessados em contribuir como o desenvolvimento mais sustentável da cidade. Os resultados da análise documental indicam que, nesse sentido, houve inovações para a cidade quando o poder público se abriu para se integrar a um sistema de governança societal que se formou durante a tramitação para aprovação do novo plano Diretor de Curitiba. No sistema interno de gestão, que poderia ter influências na política pública de 
cicloturismo urbano, os resultados das entrevistas indicam a necessidade de reformulação do modo de trabalho entre as instituições para viabilizar iniciativas intersetoriais. Esse seria um dos meios para colocar as atividades ciclísticas como estratégicas para o turismo local. Além do turismo, a viabilização da utilização de bicicletas poderia se constituir em opção ambientalmente eficiente de transporte urbano mais sustentável. Entretanto, historicamente em Curitiba, nos poucos momentos que pareceu ter sido priorizado, o modal bicicleta foi colocado como meio para suprir insuficiências do sistema de transporte coletivo por ônibus ou, ainda, para trabalhadores de baixa renda para os quais o valor das passagens eram limitantes para a sua mobilidade na cidade.

A articulação de órgãos e instituições e desses com outros atores do sistema de governança urbana societal de Curitiba é bastante baixa. Os órgãos públicos, por consequência, tendem a trabalhar mais setorialmente. Entre órgãos e instituições públicas, organizações da sociedade civil organizada e com o Poder Público local (Executivo e Legislativo), a articulação é mais sustentada por questões ideológicas do que práticas. Apesar disso, nos últimos anos foi conseguido a inserção das atividades cicloviárias em instrumentos importantes de planejamento urbano, como o novo Plano Diretor da cidade. Nesse plano, a bicicleta tem como desafio passar da visão clássica de transporte alternativo de deslocamento de mão de obra e de meio de lazer em finais de semana para se colocar com elemento importante para mobilidade urbana e para atividades turísticas.

\section{REFERÊNCIAS}

ANDRADE, V., RODRIGUES, J., MARINO, F., \& LOBO, Z. (Eds.). (2016). Mobilidade por bicicleta no Brasil. Rio de Janeiro: PROURB/UFRJ.

BAČLIJA, I. (2010). Urban management. from University of Ljubljana

BAČLIJA, I. (2013). Reconceptualisation of urban management: Evidence from eu cities. Theoretical and Empirical Researches in Urban Management, 8(1), 30-50.

BORDENAVE, J. E. D. (1995). O que é Participação (6a ed.). São Paulo: Editora Brasiliense.

CAMPBELL, T., \& FUHR, H. (Eds.). (2004). Leadership and Innovation in Subnational Government: Case Studies from Latin America. Washington: The World Bank.

DIJK, M. P. V. (2007). Urban management and institutional change: An integrated approach to achieving ecological cities (16).

DOWBOR, L. (2001). Descentralização e participação: as novas tendências. São Paulo: Versão no prelo.

DUARTE, F., \& FREY, K. (2008). Redes Urbanas. In F. Duarte, C. Quandt, \& Q. Souza (Eds.), O Tempo das Redes (pp. 155-178). São Paulo: Editora Perspectiva.

DUARTE, F., PROCOPIUCK, M., \& FUJIOKA, K. (2014). 'No bicycle lanes!' Shouted the cyclists. A controversial bicycle project in Curitiba, Brazil. Transport Policy, 32, 180-185.

FEBRES-CORDERO, M. E. (2011). La gestion pública del urbanismo. Revista Venezolana de Gestión Pública, 2(2), 175-203.

FERRO, F. (2013). Audiência Pública, para debatermos sobre o "Uso das Bicicletas no Brasil e as Políticas Governamentais de Incentivo a Utilização deste Modal de Transporte".

FREY, K. (2007). Governança urbana e participação pública. RAC-eletrônica, 1(1), 136-150.

GOULART, J. O., TERCI, E. T., \& OTERO, E. V. (2016). Planos diretores e participação política: políticas públicas de planejamento entre o empresariamento e o estatuto da cidade. Revista de Administração Pública, 50, 455-476. 
GUERRA, E. (2002). Citizenship knows no age: children's participation in the governance and municipal budget of Barra Mansa, Brazil. Environment and Urbanization, 14(2), 71-84.

HAGUE, C., \& MCCOURT, A. (1974). Comprehensive Planning, Public Participation and the Public Interest. Urban Studies, 11(2), 143-155. doi:10.1080/00420987420080311

HENNINGSSON, M., BLICHARSKA, M., ANTONSON, H., MIKUSIŃSKI, G., GÖRANSSON, G., ANGELSTAM, P., . . JÖNSSON, S. (2014). Perceived landscape values and public participation in a road-planning process - a case study in Sweden. Journal of Environmental Planning and Management, 58(4), 631-653.

HERNÁNDEZ, X. (2004). La gestión urbana desde el enfoque de desarrollo económico. Revista de Ciencias Sociales y Humanidades(99), 317-329.

HOURIHAN, K. (1987). Local Community Involvement and Participation in Neighbourhood Watch: A Case-study in Cork, Ireland. Urban Studies, 24(2), 129-136. doi:10.1080/713703878

IPPUC. (1977). Bicicletas em Curitiba.

IPPUC. (1995). Estudo preliminar sobre o perfil do ciclista da rede de ciclovias de Curitiba.

ITDP. (2012). Lei de Mobilidade Urbana 12.587/12.

JACOBSEN, P. L. (2003). Safety in numbers: more walkers and bicyclists, safer walking and bicycling. Injury Prevention(9), 2005-2009.

JARUGA, R. (2014). Ata $3^{\mathrm{a}}$ audiência pública do plano diretor de curitiba sobre a mobilidade ciclovia da Comissão de Urbanismo e Obras Públicas. Curitiba: Câmara Municipal de Curitiba

KOOIMAN, J. (2005). Gobernar en gobernanza. In A. C. i. Martinez (Ed.), La gobernanza hoy: 10 textos de referencia (pp. 57-81). Madrid: Instituto Nacional de Administración Pública.

KOOIMAN, J., \& VLIET, M. V. (2000). Self-governance as a mode of societal governance. Public Management: an International Journal of Research and Theory, 2(3), 359-377.

KULL, M., \& TATAR, M. (2015). Multi-Level Governance in a Small State: A Study in Involvement, Participation, Partnership, and Subsidiarity. Regional \& Federal Studies, 1-29.

MCCANN, E. (2017). Governing urbanism: Urban governance studies 1.0, 2.0 and beyond. Urban Studies, 54(2), 312-326.

MIRANDA, A. C. M. (2014). Ata $3^{a}$ audiência pública do plano diretor de curitiba sobre a mobilidade ciclovia da Comissão de Urbanismo e Obras Públicas. Curitiba: Câmara Municipal de Curitiba

NATARAJ, G. (2014). Ata $3^{a}$ audiência pública do plano diretor de curitiba sobre a mobilidade ciclovia da Comissão de Urbanismo e Obras Públicas. Curitiba: Câmara Municipal de Curitiba

NOUSIAINEN, M., \& MÄKINEN, K. (2014). Multilevel Governance and Participation: Interpreting Democracy in EU-programmes. European Politics and Society, 16(2), 208-223.

PMC. (2008). Proposta Preliminar do Plano de Mobilidade Urbana e Transporte Integrado.

PMC. (2016). Novos projetos dobraram a capacidade cicloviária da cidade.

RADZIK-MARUSZAK, K., \& BÁTOROVÁ, M. (2015). Citizen Participation and Engagement in Urban Governance: Perception of Finnish and Polish Local Officials. NISPAcee Journal of Public Administration and Policy, 8(1), 85-110.

RíOS FLORES, R. A., TADDIA, A. P., PARDO, C., \& LLERAS, N. (2015). Ciclo-inclusión en América Latina y el Caribe: Guía para impulsar el uso de la bicicleta. 
ROSA, A., PROCOPIUCK, M., \& FREY, K. (2016). Governança pública, redes sociotécnicas e políticas ambientais urbanas. Curitiba: Pucpress.

SINGH, N. (2006). Women Women's s Participation in Local Water Governance: Understanding Institutional Contradictions. Gender Technology and Development, 10(1), 61-76.

SNTMU. (2007). Caderno de referência para elaboração de Plano de Mobilidade por Bicicleta nas Cidades.

STUBBS, M., LEMON, M., \& LONGHURST, P. (2000). Intelligent Urban Management: Learning to Manage and Managing to Learn Together for a Change. Urban Studies, 37(10), 1801-1811.

TUNSTALL, R. (2001). Devolution and User Participation in Public Services: How They Work and What They Do. Urban Studies, 38(13), 2495-2514.

VÁSQUEZ CÁRDENAS, A. V. (2013). Las políticas públicas urbanas como proceso plural. Enfoques de política urbana y gobernanza urbana. Estudios Políticos(42), 218-241.

WINTERS, M., TESCHKE, K., BRAUER, M., \& FULLER, D. (2016). Bike Score $®$ : Associations between urban bikeability and cycling behavior in 24 cities. International Journal of Behavioral Nutrition and Physical Activity, 13(18), 1-10.

WONG, S.-W., TANG, B.-S., \& VAN HOREN, B. (2006). Strategic urban management in China: A case study of Guangzhou Development District. Habitat International, 30(3), 645-667.

XAVIER, G. N. A. (2007). O cicloativismo no Brasil e a produção da lei de política nacional de mobilidade urbana. Em tese, 3(2), 122-145.

ZAMANI, A. A., SHALI, H., MIRALANAQ, M. M., \& HADI, N. (2014). A survey of the role of urban management in physical development of the city. Journal of Social Issues \& Humanities, 2(12), 348-357.

ZHANG, L., ZHANG, J., DUAN, Z.-Y., \& BRYDE, D. (2015). Sustainable bike-sharing systems: characteristics and commonalities across cases in urban China. Journal of Cleaner Production, 97, 124 -133. 